\title{
GABRIEL MARCEL AND THE PROBLEM
}

\section{OF KNOWLEDGE}

One of the most disconcerting features of twentieth century postmodernism is its attack on the objectivity of knowledge. The beginnings of this attack can be traced back to the existentialists, especially Heidegger, and his notion of "thematizing" 1 . Heidegger develops this notion against the backdrop of his distinction between the realm of being-in-the-world and the realm of conceptual knowledge. He suggests that conceptual knowledge itself is very often carried out by the human subject in relation to the subject's everyday, particular projects, and is, therefore, in some crucial sense, relative to the context in which it is practiced. This way of explaining the origin and role of conceptual knowledge in human experience was to have great influence, and indeed it was to become standard in subsequent movements in European philosophy, i.e., structuralism, hermeneutics, critical theory, and deconstruction.

Although the precise nature of the relationship between the realm of being-in-the-world and the realm of conceptual knowledge was nowhere carefully articulated by philosophers from any of these movements, the main point raised by Heidegger became a mainstay of contemporary European thought: that, in a crucial sense, conceptual or theoretical knowledge of any type was not objectively true, but was relative to the context (however broadly or unclearly this context was defined) in which the community of enquirers lived. Philosophers such as Roland Barthes advanced the view that there can be no single objectively true, trans-historical meaning, no timeless or extra-linguistic essences, and that any attempt to suggest otherwise can be unmasked as nothing more than an attempt to impose a particular ideology on the masses. This move towards relativism and ultimately skepticism about the nature of knowledge

1See M. Heidegger, Being and Time, trans. by J. Macquarrie and E. Robinson (New York: Harper and Row, 1962), pp. 414ff; see also J. Richardson, Existential Epistemology (Oxford: Clarendon Press, 1986), pp. $49 f f$. 
reached its fullest and most ingenious expression in the work of Jacques Derrida.

Derrida claims that all identities (essences, forms, substances, kinds, etc.) involve their relations and differences. However, since relations and differences are constantly changing in history, this means that identity (i.e., meaning) must be forever postponed or deferred. Hence, no knowledge can be objective in the sense that it is trans-historical or transcendental, or independent of all viewpoints or contexts. Rather, all identities (and hence all meanings), including those which make logic and rationality possible, are relative to history and culture.

While I believe that these relativistic and skeptical tendencies in the thought of Derrida and Barthes, and of other continental philosophers who hold very similar views (such as Foucault) cannot be successfully defended, that issue will not be my concern here. But, briefly put, Derridean inspired postmodernism cannot avoid either of two very serious objections, both of which are, in my view, fatal to its attack on the objectivity of knowledge and meaning. First, if deconstruction itself is a true theory, i.e., a theory which tells us the way the world really is, or how things stand essentially, then its proponents appear to be committed to those extra-linguistic truths, and timeless essences, which they officially deny [E.g: "There is not a single signified that escapes ... the play of signifying references that constitute language" (Derrida); "The book itself is only a tissue of signs. . ." (Barthes) ${ }^{2}$ ]. Secondly, if deconstruction is not a true theory, and can make no claim to objective truth, and is relative to history and culture (i.e., if it too can be deconstructed), then it is difficult to see why (or indeed how) one could accept it or take it seriously3.

2Jacques Derrida, Of Grammatology, trans. by G.C. Spivak (Baltimore: Johns Hopkins U.P., 1976), p. 7; Roland Barthes, Image-MusicText, trans. by S. Heath (New York: Hill and Wang, 1977), p. 147.

3 See Dallas Willard, "Predication as Originary Violence: A Phenomenological Critique of Derrida's View of Intentionality", in Gary B. Madison (ed.), Working Through Derrida (Evanston: Northwestern U.P., 1993), pp. 120-136. 
One of the motivations of Derridean inspired postmodernism (and this may not be its main motivation) is a desire to move away from abstract, speculative systems of meaning more typical of traditional philosophy, in the direction of a philosophical approach which would do justice to the subjectivity and individuality of the human person. This was a clear theme in the work of the existentialists, who held that human subjectivity was not only important, but that it had profound philosophical significance. However, a serious problem arises if one takes the Heideggerian-Barthian-Derridean route towards a philosophy based on human subjectivity. In their desire to give almost absolute priority to the human subject, these philosophers seem unable to avoid relativism, skepticism and ultimately nihilism about knowledge, language, and meaning. This was a problem which haunted existentialist philosophers such as Sartre and Camus in the domain of ethics; in subsequent philosophical movements, it haunts philosophers in the domains of metaphysics and epistemology.

In this paper, I wish to suggest that Gabriel Marcel's work can help us with precisely this problem: i.e., with the problem of trying to ensure a significant role for the human subject in philosophy without sacrificing the objectivity of knowledge. Although it is appropriate to describe Marcel as a (Christian) existentialist philosopher, it is also appropriate, in my view, to describe him as a realist who believes in the objectivity of knowledge. That is to say, Marcel believes that the objects of our experience are real, and can be known objectively by all in conceptual knowledge just as they are in themselves. However, he is also undoubtedly committed to the importance of human subjectivity when dealing with philosophical problems, and indeed he is extremely sympathetic with the general shift of the movement of existentialism away from the abstract systems of traditional philosophy to a more concrete philosophy of the subject. In this paper, I will attempt to outline how Marcel's philosophy offers us a way to do justice to, and maintain the priority of, human subjectivity and individuality without falling into the relativism and skepticism which has tended to accompany such notions.

The way of reading Marcel which I will present here is not developed in any detail in Marcel's thought, although I believe it is quite explicitly stated in general outline. And although a certain amount of reconstruction is necessary, as it is in the exposition of 
many of Marcel's main themes, I think that there is sufficient evidence both textually and thematically to claim with reasonable certainty that the view which I will briefly sketch here was held by him. At the very least, I wish to claim that the view which I will discuss in these pages is fully compatible with Marcel's thought. I will concentrate on an analysis of the two realms of knowledge identified by Marcel, that of being-in-asituation, or what I will sometimes call "situated involvement", and that of conceptual thought. I will attempt to illustrate the difference between the two realms, as well as the nature of the relationship between them, in terms of what I call particular and abstract ideas. Although Marcel does not use these terms, I think they do help to clarify certain key ideas in his thought.

It is an important theme in Marcel's work that our ideas essentially involve both a body and a world which contribute fundamentally to their particular character. Marcel holds that if we examine our ideas carefully we will discover, first, that they involve in a crucial sense a body and a world, and, secondly, that so called "clear and distinct ideas" (or abstract ideas) are simply abstractions from this more fundamental level of "situated involvement" in which the "objects" 4 of our experience have very different (personal, particular) meanings for the individual than the meanings presented in the mind in "clear and distinct" (abstract, public) ideas. We must now elaborate these points in more detail.

According to Marcel, when I encounter an "object" in my experience I do not simply "regard" it as an "object" in the abstract sense of object (i.e. in the sense of "object" to which our concept would correspond). I do not "just look at it" and see it as an isolated object located in the cause and effect world of space and time, all ready for inspection for the purposes of obtaining knowledge about

4The word "object" is placed in inverted commas here to indicate that it should be understood in a broad sense. "Objects" is intended to refer to not just physical objects, but to any aspect of experience which becomes a content for the mind. A newspaper, a walk, feeling cold, and a conversation with a friend, are all possible "objects" of experience in Marcel's sense. 
it5. This is not what goes on in our ordinary everyday experience. For in ordinary everyday experience, there are certain features of existence which place the subject in a unique situation. First, the subject, for Marcel, is irreducibly sentient, and is not exclusively a thinking, or knowing, or self conscious subject (though Marcel does not wish to deny the importance of these aspects of human experience). 6 Secondly, through the contingencies of physical birth, the subject is placed in a specific context by its physique, race, gender, spatial and temporal location, national identity, cultural and economic situation, etc. 7 As Marcel puts it, "The essence of man is to be in a situation"8.

The significance of the embodied context of the subject for the subject's ideas will be illustrated clearly in any phenomenological description of what I call an individual subject's particular ideas. I introduce the term "particular idea" here to distinguish this kind of idea from an "abstract idea". A particular idea is the idea of an object a particular human subject in a particular human situation has; whereas an abstract idea is the idea of that same object that all human subjects share. A further, and higher, level of abstraction would reveal the general idea of objects of that kind. For example, my idea of my copy of Marcel's The Mystery of Being (Vol. I) is a particular idea, different in important respects from the particular idea others have of Marcel's book, and also different from the abstract idea of that same book which all people acquainted with the book share. The concept "book" would then involve a further level of abstraction. Obviously there will

5See G. Marcel, Being and Having, trans. by L. Farrar (Boston: Beacon Press, 1951), pp. 10-11; also G. Marcel, The Mystery of Being (Vol. I), trans. by G.S. Fraser (Chicago: Regnery, 1951), pp. 125ff.

6See The Mystery of Being (Vol. I), p. 104; also Being and Having, p. 11.

$7 \mathrm{l}$ am indebted to Sonia Kruks for this description of Marcel's notion of "being-in-a-situation". See her Situation and Human Existence (London: Unwin, 1990), p. 12.

8G. Marcel, Creative Fidelity, trans. by R. Rosthal (New York: Farrar, Strauss, 1964), p. 83. 
be points of similarity and overlap in any comparison of different subjects' particular ideas of Marcel's book. Yet the differences are crucial because it will turn out that the particular ideas of each subject bear the marks which are peculiar to, and which are unique in, that particular subject's embodied situation in existence. And since no two subjects have identical embodied situations (although they may have similar situations), then each subject's particular ideas will be importantly different from every other subject's particular ideas. Of course, this distinction needs to be explained and elaborated in more detail by means of an example. Marcel refers to the example of the peasant and his relationship to the soil. It will be helpful to make this example as concrete as possible (more concrete than Marcel makes it) in an attempt to clarify Marcel's main point.

Let us say that the peasant is plowing his favorite field in order to plant potatoes. This is the field for which he saved his earnings over several years, and then acquired by a skillful piece of bidding at an auction. It has consistently yielded good crops of potatoes for him. Further, he always seems to get a good financial return for the crops harvested in this particular field. He nearly always plants this field at his favorite time of year, and it plows easily. In this peasant's unique existential situation, it is quite easy to see that he does not see his land as an (abstract) "object". The meaning of the concept "field" is not identical for him with the meaning the field has for him in his personal experience. So when he says to the neighboring farmer, "I am plowing the field today", the concept "field" which is utilized in this remark, and which. both men share, and which makes possible communication between them, does not fully capture, convey, or adequately represent the actual meaning the field has for the peasant in his unique existential situation. Nor will the concept capture the existential meaning the field in question has for the neighboring peasant either. Nor is it intended to. Of course, the (abstract) concept "field" has a similar meaning for both peasants. The different existential meaning the field in question has for both men will be defined by each one's unique existential situation, or condition, in their world. Further, the peasant does not need to appreciate in any clear way the distinction between the conceptual meaning of the field and what we might call its non-conceptual, existential meaning. However, it is a crucial distinction nonetheless. 
Let us speculate further on what the field in question might mean to this particular peasant. That is, let us try to describe phenomenologically the peasant's particular idea of this field, rather than his abstract idea of the field. It is clear that he does not look upon this piece of land as just another field, as the passerby might look upon it. Rather, as Marcel puts it, his soil transcends everything he sees around him; it is linked to his inner being, and by that we must understand not only his acts, but also his sufferings 9 . In other words, the peasant's experience with, and participation in, the activity of plowing the soil in this particular field in order to plant his potatoes is internally related to his embodied situation in existence: to his past activities in relation to this field (how he acquired it, worked it in the past, etc); to his future projects with regard to the soil; to his day to day relationship with the soil; etc. All of these experiences help to define the meaning of this field for this particular peasant. And since no two individuals have identical situations in existence, the existential meaning of any common object of their experience will never be identical for both of them 10 .

Marcel compares the peasant's experience of the soil with that of the tourist or artist, saying that "the contrast between the soil experienced in this way as a sort of inner presence, and anything that a landscape may be to the amateur of beauty who appreciates it and who selects a few epithets from his stock to pin down its salient notes, is surely as deep and as firmly rooted as could be" 11 . An artist, for example, will also participate (or be "involved") in such a landscape, but in a way which will be quite different to that of either the peasant or the tourist. The point is that the particularidea each has of this field is defined by the embodied context or "situated involvement" of each in their world, or, in other words, by the "situated involvement" of each

9See The Mystery of Being (Vol. I), p. 116.

10lt was in this sense that Bergson argued that conceptual knowledge had a practical use. For it allows us to speak of objects, and to utilize objects, which each person inevitably experiences differently. See Henri Bergson, An Introduction to Metaphysics, trans. by T.E. Hulme (New York: Macmillan, 1955 ed.), pp. 44-45.

11 The Mystery of Being (Vol. I), p. 116. 
one's life. As Marcel says, "Our itinerant condition cannot be separated from our given circumstances, from which in the case of each of us that condition borrows its character"12.

It is important to make some clarifications in our description of the peasant's experience of the soil. The experiences or attitudes are not just suggestions that the soil and landscape throw out to the peasant or to the artist, nor are either simply being reminded of past events through their various present experiences of the soil, nor are they engaging in simple imaginings. Rather, this is what the soil means for each. Their experiences take place at the level of existential contact, and not at the level of abstraction. Undoubtedly, there is an important relationship between the concept (the abstract idea) and the particular idea of each object of experience (and the history of philosophy has yielded many different accounts of this relationship), yet the key point for Marcel is that the concept is abstract, general, public, whereas the particular idea the individual has is particular, personal and private. In short, the experiences each person has (which give rise to the particular ideas) are what they are through the involvement of a particular embodied subject with this soil. It is this level of existential contact which we must evoke in order to get even a glimpse of the meaning of each individual's experiences.

Let us mention very briefly a second example. When I pick up (say) a novel from my desk, one thing is clear. I do not see it fundamentally as an (abstract) object, as merely "another book". Because I am an embodied, existential subject, I do not initially understand (or "grasp" in conceptual knowledge) the book in isolation from my experience as an embodied being-in-a-situation. That is to say, it is impossible for the book to have only an abstract meaning for me. I see the "object" as related to me in a way which is defined by my situation as an embodied subject. I will experience the book as fitting into, and as part of, a set of complex relationships. I will recognize the book, and identify it as having a certain history, and as relevant for certain future tasks. This is part of what this particular book means for $m e$. It is part of my experience, and it is my experience which gives

12/bid., p. 134. 
rise to my particular idea of this book. In the ordinary, everyday world of the individual subject, the "objects" of experience bear a certain relation to the individual subject which they do not bear to anybody e/se. To treat the object in isolation from the subject's own experiential context is to distort the meaning of the object for the individual in question. It is to resort to an (abstract) object which, in fact, is not any particular subject's object.

To put the issue in a slightly different way, there are no "books" (understood in an abstract sense) in my experience at the level of "situated involvement", there is only this or that particular book, etc. My "particular ideas" of these books will be constituted, not by some preformed judgment about what constitutes a "book", nor by some abstract concept I have of "book" which I then apply to all objects of this kind which I encounter in my experience. Rather, my "particular ideas" of books will be constituted by the fact that I am habitually in contact with and involved with particular books as meshed in my projects, that I have certain expectations with regard to them, that I have certain attitudes towards them, etc. These cases constitute certain specific ways books affect $m e$. They are all defined by the web of relationships books enter into with regard to my particular situation in existence. Marcel expresses it thus: "[The] object possesses . . . the power of affecting in a thousand different ways the being of the person who contemplates it ..."13. This analysis explains the realization we often have that our ideas have our own personal quality or stamp on them, why a book appears short to one person but long to another, why we feel at home in one place, and a stranger in another, why even the taste of raspberries can have different

13G.Marcel, "Existence and Objectivity", in T. Busch (ed.), The Participant Perspective: A Gabriel Marcel Reader (Lanham: U.P. of America, 1987), p. 52. Marcel's analysis influenced Merleau-Ponty and Ricoeur. On this point, see Ricoeur's remarks in G. Marcel, Tragic Wisdom and Beyond, trans. by S. Jolin \& P. McCormick (Evanston: Northwestern U.P., 1973), p. 222. 
meanings for different people, etc ${ }^{14}$.

We must now focus more explicitly on the relationship between these two realms: the realm of being-in-a-situation (particular ideas), and the realm of conceptual knowledge (abstract ideas). It will also be useful to pay close attention to Marcel's notion of the realm of primary reflection, and how this realm differs from the realm of being-in-asituation. This will help us to explain how Marcel safeguards the objectivity of knowledge. The key point to note is that the objectivity of knowledge is preserved precisely in the move to abstraction. In the act of abstraction, we do not take the fact of embodiment, and the nexus of relationships defined by our situation as embodied subjects, into account. Rather, we try to set all of this aside. What happens at the level of thought is that the images and pictures we have in our mind are separated from our "situated involvement" with the world, and their essential features are reified in conceptual knowledge. In short, in the act of abstraction, thought becomes disinterested, and is not completely faithful to how objects actually affect us in our experience.

Marcel is drawing attention to the point that, prior to conceptual knowledge, all the "objects" 15 of the individual's experience are permeated with special, particular meanings, meanings which are defined and conditioned by the individual subject's embodied situation in the world. But in conceptual knowledge, certain essential features of these meanings are (in some cases often with great difficulty) abstracted by the intellect and presented as "objects" of knowledge available for all to consider. But obviously something will be lost here in this process of abstraction - that which has been mine in the experience, that which "situates" it in my life and makes it personal16. Hence our inability to adequately express many of our

14See Creative Fidelity, p. 27 and p. 89 for a discussion of the notion of "feeling at home" in a particular place. See The Mystery of Being (Vol. I), p. 61 , for a discussion of the raspberries example. See also D.E. Cooper, Existentialism (London: Blackwell, 1990), p. 80.

15 See note 3 above.

16See The Mystery of Being (Vol. I), pp. $92 \mathrm{ff}$. 
experiences in concepts, and Marcel's emphasis throughout his work on the creative role of the artist, and on dramatic art, as a way to evoke or reveal the nature of the human subject in its world17.

We might say that in our ordinary everyday experience of "situated involvement" we are operating at a level of, to use another of Marcel's phrases, submerged participation, and that in reflective thought we disengage from this submerged participation by means of a process of abstraction that is an integral part of the process of thought 18 . This process of abstraction occurs in what Marcel calls the realm of primary reflection. According to Marcel, primary reflection "tends to dissolve the unity of experience which is first put before it"19; and he also says that reflection "is in a sense one of life's ways of rising from one level to another"20. Primary reflection includes normal, everyday reflection, as well as more complex theoretical thinking, and it involves conceptual generalizations, and the use of abstract thinking. This is the kind of reflection which characterizes the type of thinking found in the sciences, mathematics, and "theoretical thinking" of any kind. It requires a "standing back" from, or abstraction from, our embodied situation in existence, and engages in an enquiry which proceeds by means of disinterested concepts, which have shareable, public, and, therefore, universal content.

According to Marcel, primary reflection normally arises when the individual is confronted by a problem at the level of experience. However, a problem requires a solution which is available for everybody21. But essential features of experience can only be

17See K.R. Hanley, Dramatic Approaches to Creative Fidelity: A Study in the Theater and Philosophy of Gabriel Marcel (Lanham: U.P. of America, 1987).

18See The Mystery of Being (Vol. I), p. 114.

19|bid., p. 83.

20lbid., p. 82.

${ }^{21}$ See ibid., pp. $4 f f$. 
presented as "problems" for everybody to consider if the individual first abstracts from the "situated involvement" which defines the lived experience of the enquirer, and these essential features can only be maintained and discussed as problems if everyone involved in their appraisal does likewise. Suppose, for example, that the peasant is plowing his field when the tractor suddenly stops working. In this instance, the peasant will "abstract" (or disengage) from his "being-ina-situation" of plowing the field and focus on the problem, i.e., on the broken tractor itself. Perhaps the peasant will notice that the distributor cable is damaged, and will set about repairing it. This problem, however, is one which could, in principle, be identified and solved by the peasant's neighbor, or by any person. Primary reflection is, therefore, problem-solving thinking. It requires abstract concepts which allow us to publicly formulate and hopefully solve problems. This is true no matter how complex the problem is.

It should be clear that the level of primary reflection is the level of objective knowledge. This is because the concepts employed at the theoretical level are objective in two crucial senses. First, they represent essential features of the objects of experience (at an abstract level) as they really are in the objects, and second, these essential features are also objective in the crucial sense that they are understood by everyone in the same way. So, to continue with our example of the peasant's problem with the distributor cable, his (and indeed everybody's) conceptual analysis of this problem will involve concepts which adequately represent essential features of the object in question as they really are, e.g. the shape of the distributor cable, its length, physical make-up, color, relationship to other engine parts, etc. Also, the neighboring peasant (and indeed anybody who contemplates the object) will understand conceptually these features in exactly the same way as the peasant. Hence, this knowledge is objective because, first, it adequately represents essential features of the objects of experience just as they are in themselves, and, secondly, it represents these features in the same way for all, regardless of each person's embodied situation in existence. Yet, in our example, the peasant and his neighbor will still have different particular ideas of the engine part. (For example, the peasant may be particularly adept, and his neighbor particularly inept, at repairing engines. These respective experiences, and various others, would therefore affect each man's particular ideas of engine parts.) 
The examples I have discussed are simple examples of conceptual abstraction, but Marcel's insights apply also to all kinds of conceptual knowledge, including more complex types, such as theories. Theories consist of organized bodies of concepts, between which there will usually be complicated logical relationships; but these concepts are still abstracted from experience. So theories too will be objectively true (if they adequately represent reality) in the sense just described. A scientific theory, for example, would be objectively true if the parts of reality represented by the concepts utilized in the theory are represented just as they really are. And, of course, these concepts will be understood in the same way by all who contemplate them ${ }^{22}$. It is true that Marcel does not elaborate in any way exactly how the mind in conceptual knowledge adequately represents key features of the objects of experience as they are in themselves. In short, he has no detailed, positive account of intentionality. (It must be pointed out that, in this respect, he is similar to most contemporary European philosophers, including Derrida). But I believe I am right in arguing that Marcel nevertheless holds that knowledge is objective in the two crucial senses which I have described. In this way, Marcel's analysis of the realm of primary reflection and the realm of experience (or existential contact) clearly does justice to the individuality of human experience, while also safeguarding the objectivity of knowledge.

So, while Marcel is keen to emphasize the philosophical significance of human subjectivity, he does not wish to compromise in any way the objectivity of knowledge, and, as we have seen, he does not. This was precisely the mistake made by Heidegger and those philosophers who were influenced by him. For it was in the move from the realm of experience (or being-in-the-world) to the realm of conceptual knowledge that contemporary European philosophy made a fatal mistake, a mistake which took it inexorably in the direction of relativism about knowledge. As mentioned at the outset of this paper, recent continental philosophers such as Derrida, influenced by Heidegger, claim that conceptual knowledge itself, just like every other experience of being-in-the-world, is relative to the context of the enquirer. This applies also, and perhaps especially to, theories, although it must be pointed out that Derrida and his followers never provide a single clear, detailed description of a concrete case

22See ibid., pp. 4ff. 
illustrating exactly how conceptual knowledge is permanently compromised by the ineluctable priority of human subjectivity.

Roland Barthes--a good representative of postmodern thinking--also claims (isn't this supposed to be an objectively true, extra-linguistic claim?) that the abstract and conceptual way of looking at things is but the product of a cultural context. This thesis is then extended to call into question the realist view which regards language as a system of reference, which represents the real world more or less as it really is. While I cannot go into the serious problems such claims face here, it is important for my purposes to make two points: 1) that these kinds of claims do face very serious, and perhaps insurmountable, logical difficulties, and 2) that Marcel avoids these difficulties, and the relativism which gives rise to them, in the way we have just seen. He avoids these unpleasant consequences by holding that the level of being-in-a-situation, or situated involvement, is what it is because of a particular context, but that this particular context does not compromise in any way the objectivity of knowledge, which remains secure on the abstract, conceptual level.

Marcel, however, famously warns against placing too much emphasis on the objectivity which is the defining characteristic of primary reflection. He does this for the good reason that many of the human subject's most profound experiences simply will not submit to the requirements of primary reflection 23 . This is because many of the individual subject's personal experiences cannot be fully captured in concepts, which, after all, are supposed to be essentially disinterested, and have sharable, public content. Marcel is particularly keen to ensure that the human subject itself is not treated in primary reflection as just another object among objects 24 . This is very important because one of the great abuses of modern thought has been its tendency to try to objectify all human experience in

23/ develop in more detail Marcel's view of non-conceptual knowledge (secondary reflection) in my "Non-Conceptual Knowledge in Jacques Maritain and Gabriel Marcel", in Curtis L. Hancock and Anthony O. Simon (eds.), Freedom, Virtue, and The Common Good (Notre Dame: University of Notre Dame, 1995).

24See The Mystery of Being (Vol. I), Chapter 2. 
concepts, and failing this, to judge that any experience which cannot be so objectified is not worthy of serious philosophical consideration. In opposition to this, Marcel holds that there is a whole range of experiences which cannot be fully objectified in conceptual knowledge 25. These experiences occur in what Marcel sometimes calls the realm of mystery, not because it is an unknowable realm, but because it is a realm which cannot be fully captured in primary reflection26. Some of the "mysteries" of Being, according to Marcel, include our particular being-in-a-situation, our experience of our own embodiment, the unity of body and mind, the nature of sensation, and the higher levels of Being: the "concrete approaches" of love, hope, fidelity and faith27.

By drawing a clear distinction between the level of being-in-asituation, and the level of conceptual knowledge, and by profoundly illuminating the nature of the relationship between them, Marcel wishes to show not only the importance, but also the limits of primary reflection. At the same time he wishes to preserve the integrity and dignity of the human person by doing appropriate justice to human subjectivity.

Approaching the matter from the other direction, we might say that Marcel wishes to show not only the importance, but also the limits of human subjectivity, and at the same time in doing this he preserves the objectivity of knowledge. He therefore has skillfully avoided compromising either human subjectivity or the objectivity of knowledge, and thus has avoided the relativistic and skeptical excesses that have plagued recent thought ever since Heidegger

${ }^{25}$ See Creative Fidelity, pp. 54ff; see also The Mystery of Being (Vol. 1), pp. 205ft; and The Mystery of Being (Vol. II), Chapter 3.

26See Creative Fidelity, p. 23. See also "Existence and Objectivity", pp. 71-72; and Being and Having, p. 117.

27See The Mystery of Being (Vol. I), pp. 100-101. For a discussion of the levels of Being in Marcel's thought, see E.L. Strauss and M. Machado, "Gabriel Marcel's Notion of Incarnate Being", in P.A. Schilpp and L.E. Hahn (eds.), The Philosophy of Gabriel Marcel (La Salle: Open Court, 1984), p. 129. 
and Sartre28.

Rockhurst College

BRENDAN SWEETMAN

28I am grateful to Doug Geivett, Curtis L. Hancock and Teresa ReedDowning for helpful comments on an earlier draft of this paper. 